\title{
Analysis of the Apparent Viscosity of Starch in Aqueous Suspension within Agitation and Temperature by Using Rapid Visco Analyzer System
}

\author{
Andrés Antonio Acosta-Osorio, Gilberto Herrera-Ruiz \\ División de Investigación y Posgrado, Facultad de Ingeniería \\ Universidad Autónoma de Querétaro \\ Cerro de las Campanas s/n, CP 76010, Quéretaro, Qro, México
}

Tel: 52-442-192-1200 ext.7007Ｅ-mail: andacos@hotmail.com; gherrera@uaq.mx

\section{Posidia Pineda-Gómez}

Facultad de Ciencias Exactas y Naturales, Universidad Nacional de Colombia, sede Manizales

Manizales A.A. 127, Caldas Colombia

$\&$

Facultad de Ciencias Exactas y Naturales, Universidad de Caldas

Manizales A.A. 357, Caldas Colombia

E-mail: posidia_pineda@yahoo.com

María de los Angeles Cornejo-Villegas

Departamento de Ciencias Químicas. Facultad de Estudios Superiores Cuautitlán

Universidad Nacional Autónoma de México

Av. $1^{\circ}$ de mayo s/n, C.P. 54740 Cuautitlán Izcalli, Edo de México, México

E-mail: angicornejo@gmail.com

Fernando Martínez-Bustos \& Marcela Gaytán

Centro de Investigación y de Estudios Avanzados del IPN

Libramiento Norponiente No 2000, Fracc. Real de Juriquilla CP 76230, Quéretaro, Qro, México

E-mail: fmartinez@qro.cinvestav.mx; marcelagaytanm@yahoo.com.mx

Mario Enrique Rodríguez-García (corresponding autor)

Departamento de Nanotecnología, Centro de física Aplicada y Tecnología Avanzada

Universidad Nacional Autónoma de México

Campus Juriquilla, CP 76230, A.P. 1-1010, Querétaro, Qro, México

Tel: 52-442-238-1141 E-mail: mariorodga@gmail.com

Received: December 6, 2011 Accepted: December 15, $2011 \quad$ Published: December 31, 2011

doi:10.5539/mer.v1n1p110 URL: http://dx.doi.org/10.5539/mer.v1n1p110

\begin{abstract}
This research relates to the analysis of a mathematical model for the interpretation of the apparent viscosity of starch aqueous suspensions during agitation, as well as the influence of the starch-water ratio in the pasting
\end{abstract}


profiles. The thermal profile of the pasting test produces several changes in the starch-aqueous suspensions that can be evaluated through the complete knowledge of the physicochemical changes in the suspension, equations that governs the system and the instrumental conditions of the impeller viscometer. Differential scanning calorimetry (DSC) and rapid visco-profile of starch-water suspension, using the same heating rate and water-starch ration, were obtained in order to study the thermal and pasting changes of the starch-aqueous suspension as a function of the thermal profile and time, The use of the pasting profile, its first and second derivate as well as the DSC thermal profile, provide information about critical process taking place in the starch-water suspension such as the swelling and gelatinization processes that affect the rheological properties. The use of different starch/water ratios allows the determination of different pasting regimes.

Keywords: Starch, Impeller viscometer, Gelatinization temperature

\section{Introduction}

Starch is a widely known polysaccharide formed by amylose and amylopectin chains; it is important as a major source of calories for human nutrition. The starch industry is large;and starch has many applications, such as food, chemistry, and petroleum, amongst others. Starch can be obtained from several agricultural crops, such as legumes (beans, peas, fava, etc), cereal (corn, wheat, rice, etc), and tubers (potato, tapioca, etc). The properties of starch depend on its amylose and amylopectin ratio and other factors as source and whole components of starch. Gelatinization is an important starch property, because it indicates changes in its crystalline structure and functionality. There are several methods to determine starch properties; for instance, the gelatinization behavior is determined by using a Differential Scanning Calorimetric (DSC) and Rapid ViscoAnalyzer (RVA).

In DSC thermogram, the gelatinization is shown as an endothermic peak located between $68^{\circ} \mathrm{C}$ and $85^{\circ} \mathrm{C}$ (Yamin et al 1997). The thermogram is also used to observe physical properties such as gelatinization, retrogradation temperatures, and enthalpies. However, it is not possible to ascertain the functionality of starch. In turn, the RVA is used to simulate food processing and to related functionality and structural properties (Copeland et al 2009). For example, the peak time and peak viscosity can be associated with the water absorption capacity. High setback values are correlated with the amylose content, and even higher setback values are considered to be an indicator of better palatability (Copeland et al., 2009).

RVA profiles have been widely studied, and some authors included first derivate analysis. Meadows (2002) studied the effect of the amylose in the pasting properties of rice flours using the first derivate of the pasting profiles. Recently Cornejo-Villegas et al. (2010) used the same criteria to study the influence of gums in the pasting properties of instant corn flours enhanced with natural fibers, both soluble and insoluble, and they found that the pasting profile is highly sensitive at lower times and temperatures (of the order of 0 to 100 s, and 50 to 70 ${ }^{\circ} \mathrm{C}$ ) to the presence of gums. Nonetheless, the use of the second derivative of the pasting profiles, which gives important information regarding the critical process, has not been reported.

In the food industry, the RVA is a good tool for obtaining information related to apparent viscosity (Cornejo-Villegas et al. 2010 and Palacios et al., 2009), but the experimental results appear as a 'black-box' in terms of their interpretation. The system carries out the measurement and only phenomenological descriptions of the pasting properties of the fluid can be done, but information related to the mathematical model and the physics required for interpretation and correct modeling of the results has not yet been reported.

Bongenaar et al. (1973) found that the use of conventional methods for determining rheological properties of fluids are not satisfactory for systems where there are suspended particles such as in the case of starch aqueous suspensions. They proposed the use of an impeller shaft that was connected to the driver motor/torque indicator system of a rotational viscometer. In this manner, they were able to measure the torque of the impeller. This investigation is important because it is the precursor to the use of an impeller in order to obtain information related to the apparent viscosity or pasting applications.

Metz et al. (1979) studied the measurement of the viscosity of a suspension using impeller viscometer systems (as a RVA) measuring the power consumption. In this research, however the particular solution of the general expression for power number, as expressed by Rushton et al. (1950), was the only focus; it neglected to take into account the behaviors of the Froude number. This fact is fundamental to establish the mechanical conditions to validate the Reynolds number.

The proper calibration of any impeller system is key to determining the apparent viscosity of a sample. The basic assumption of the impeller viscometers is that the shear rate constant is independent of the rheological properties of the fluid. The experimental system has to be able to convert the torque reading at different stirrer speeds into a shear stress/ shear rate relationship (Metz et al., 1979). The system has to be calibrated for both Newtonian and 
non-Newtonian fluids. Pimenova et al. (2003) used Newtonian fluids namely silicone oil and glycerol, to determine the impeller constant, whilst using non-Newtonian fluid it was possible to determine the shear rate constant. Xanthan and Guar gums solutions were used as non-Newtonian fluids because their rheological behaviors at low shear rates is similar to that of yield stress fluid. Pimenova et al. (2003) found small differences between determinations of the shear rate constant $(\mathrm{k})$ with helical impeller and cone-and-plane viscometer calibration. Novotná et al. (2001) used the helical ribbon impeller to determine the apparent viscosity and consistency of baby foods. The use of this kind of system has the advantage of setting suspensions of coarse particles, for which the coaxial cylinders cannot be used; in order to calibrate the system honey was used as Newtonian fluid. According to these authors, if a mixer is used to obtain rheological measurements, the creeping flow regimen should be kept constant during the experiment. This can be achieved by keeping the Reynolds number under 10, and the Froude number equal to 1. Eriksson et al. (2002) use the same kind of system to study the apparent viscosity of fluid foods such as starch solutions, soups, sauces, tomato pastes, tomato purees, and juice concentrates. They created a complete calibration method for Newtonian and non-Newtonian fluids.

Conventional rheometers cannot be used in the case of starch cumuli, because the particles under study have similar dimensions than the gap used in these kinds of instruments. Also important are the changes taking place in the particles as a function of time and temperature. On the other hand, when the sample being studied is placed conventional rheometer geometries the measuring process may result in the partial destruction of the internal structure. Also, a separation phase may occur while the measurement is in progress (Abdellatif et al., 2002). The rheological problem to determine the apparent viscosity has been studied by Quemada (1977, 1978 a, b). This author took into account the existence of inter-particle force within the concentrate suspension. The forces are able to form aggregates or cumuli, which are responsible for significant viscosity changes. According to Quemada's model, the increase of effective volume fraction of particles in the suspension produces increases in the apparent viscosity. In Quemada's model the prediction of the breakdown of the aggregates, along with the characteristic relaxation times, are noticeable.

The aim of this research was to study the pasting profile of several starch concentrations. Also, analyses of the first and second derivative were included in order to understand the effect of these variations in the pasting profile. The mathematical and physical meaning of the solution proposed by Metz et al. (1979), for the power number equation (Rushton et al., 1950), was explored. We explain specific operating and geometrical considerations for the measurement of apparent viscosity.

\section{Material and Methods}

\subsection{Particle size determination}

The particle size of corn starch from Newport (Australia, part number 102102) that is the same used to carry out pasting profile was determined through Mastersizer MS2000 of Malvern Company (United Kingdom). The test was carried out using dry dispersion module in vacuum (Scirocco), with 2 bars of pressure and feed rate $50 \% .6$ $\mathrm{g}$ of starch was used (part number 102102) from Newport, Australia. The reported value corresponds to the average of three measurements.

\subsection{Scanning electron microscopy}

The corn starch sample (SS) morphology was inspected using a scanning electron microscope (SEM) (JEOL JSM-6060LV, Japan). The starch sample was coated with gold and the beam energy was $20 \mathrm{kV}$, in order to obtain the excitation of all elements.

\subsection{DSC analysis}

In order to study the influence of water content in the starch-water suspension, and to emulate the RVA conditions, with different water content $(70,75,80,84$ and $87 \%$ of moisture), DSC thermograms at different moisture content were obtained. The samples were placed in aluminum hermetic sealed pans, they were stabilized at room temperature during 30 minutes, and then heated in a ramp at $5.7^{\circ} \mathrm{C} / \mathrm{min}$. That is the same ramp used in the RVA experiments presented below. DSC analysis was carried out in a Q100 TA Instruments calorimeter. DSC experiments accurately determine the gelatinization temperature range under the aforementioned condition. The onset points obtained at the beginning (To) and at the end (Te) of the gelatinization peak, as well as the gelatinization peak temperature (Tg) were obtained with the Universal Analysis 2000 TA instrument software.

\subsection{Apparent viscosity}

The apparent viscosities of the starch aqueous suspensions for different starch concentrations were determined using a Rapid Visco-Analyzer (Super RVA-4; Newport Scientific Pty, Australia). Samples were adjusted to 14\% 
moisture content, and distilled water was added to keep the total weight of water and sample constant at $28 \mathrm{~g}$. Starch from Newport (Australia, part number 102102) was used.

In order to study the effect of starch concentration in the RVA profile the follow samples were tested: $1 \mathrm{~g}$ of starch and $27 \mathrm{~g}$ of water ( $96.4 \%$ moisture); $2 \mathrm{~g}$ of starch and $26 \mathrm{~g}$ of water ( $92.8 \%$ moisture); $3 \mathrm{~g}$ of starch and $25 \mathrm{~g}$ of water ( $89.3 \%$ moisture), $4 \mathrm{~g}$ of starch and $24 \mathrm{~g}$ of water ( $85.7 \%$ moisture), and $4.5 \mathrm{~g}$ of starch and 23.5 of water ( $84 \%$ moisture). Initially, the temperature of the system was $50{ }^{\circ} \mathrm{C}$, and it remained constant for $1 \mathrm{~min}$. Then the sample was heated for $7.5 \mathrm{~min}$ from $50^{\circ} \mathrm{C}$ to $92^{\circ} \mathrm{C}$, and then held at a constant temperature of $92^{\circ} \mathrm{C}$ for $5 \mathrm{~min}$. The samples were cooled down to $50^{\circ} \mathrm{C}$ in $7.5 \mathrm{~min}$, finally this temperature was kept constant for $2 \mathrm{~min}$. The total time for this test was 23 minutes. The operation conditions were: vessel diameter $0.037 \mathrm{~m}$ andheight $0.068 \mathrm{~m}$; impeller diameter $0.034 \mathrm{~m}$ and height $0.013 \mathrm{~m}$, the frequency of the system was $160 \mathrm{rpm}$.

\subsection{Mathematical Model}

A model to determine the apparent viscosity of suspensions can be described in detail through the use of theory of dimensionless numbers and the theorem of Pi-Buckingham that was demonstrated by Rushtonet al. (1950). To develop this theorem, it is necessary to determine what variables are the most important in order to define the particular system. In the case of impeller viscometer, the following variables can be defined for a system composed by vessel, fluid, and impeller, see Figure 1 and table 1.

The result of this mathematical approach can be expressed the following equation:

$$
P_{0}=K_{c} \operatorname{Re}^{m} \mathrm{Fr}^{n}
$$

Where $\mathrm{K}_{\mathrm{c}}$ is a constant, Re is a Reynolds number, Fr is a Froude number and $\mathrm{P}_{0}$ is a Power number, and $\mathrm{K}$ can be written as follows:

$$
K_{c}=\left(\frac{D}{T d}\right)^{X_{1}}\left(\frac{D}{H}\right)^{X_{2}}\left(\frac{D}{C}\right)^{X_{3}}\left(\frac{D}{J}\right)^{X_{4}}\left(\frac{D}{S}\right)^{X_{5}}\left(\frac{D}{L_{b}}\right)^{X_{6}}
$$

$\mathrm{K}_{\mathrm{c}}$ is characteristic of the impeller and its environment.

The Froude number, Reynolds number and Power number are:

$$
\begin{gathered}
F r=\frac{N^{2} D}{g} \\
R e=\frac{\rho N D^{2}}{\mu} \\
P_{0}=\frac{P}{\rho N^{3} D^{5}}
\end{gathered}
$$

Thus, equation can be rewritten as follows:

$$
P_{0}=\left(\frac{D}{T d}\right)^{X 1}\left(\frac{D}{H}\right)^{X 2}\left(\frac{D}{C}\right)^{X 3}\left(\frac{D}{J}\right)^{X 4}\left(\frac{D}{s}\right)^{X 5}\left(\frac{D}{L a}\right)^{X 6} \operatorname{Re}^{m} F r^{n}
$$

\subsubsection{Uniqueness solution problem}

Equation 1 shows the complete solution for the system involving the geometrical, physical and instrumental conditions required to measure the apparent viscosity of a fluid during agitation conditions with an impeller viscometer (RVA). This equation includes three different parameters that can be analyzed in detail: The constant $\mathrm{K}_{\mathrm{c}}$, and the Froude, and Reynolds numbers. In this section, a specific solution concerning this equation will be studied whereby the apparent viscosity of the suspension is the primary focus.

Equation 1 has multi-parametric and multiple solutions. Thus in order to obtain a singular solution for impeller viscometer it is necessary to reduce the number of free parameters. One way to do this is by choosing the geometrical dimension of the vessel, and setting a specific impeller shape and dimensions that also affect the $\mathrm{K}_{\mathrm{c}}$ value. In the case of a commercial system, this parameter is fixed by choosing a specific vessel.

\subsubsection{Analysis of the Froude number}

Eq. 1 is the complete equation used to determine the apparent viscosity of starch aqueous suspension utilizing an impeller viscometer such as RVA. The Froude number is related to the ratio between centrifugal and gravitational accelerations. One of the multiple solutions of equation 1 is present when $\mathrm{Fr}=1$ and any value of $\mathrm{n}$. When $\mathrm{Fr}=1$ 
this equation has a physics sense. For this particular solution, there is a lineal relationship between centripetal and gravity acceleration; in this moment the system is completely agitated without vortices. Now, eq. 1 can be rewritten as:

$$
P_{0}=K_{c} R e^{m}(1)^{n}
$$

In the case of commercial systems (Rapid Viso Analizer), it uses an impeller with $\mathrm{D}=0.0348 \mathrm{~m}$ and $\mathrm{g}=9.8 \mathrm{~m} / \mathrm{s}^{2}$, eq. 3 produces as a result $\mathrm{N}=160 \mathrm{rpm}$, corresponding to the frequency of the impeller that used for any experiment. To date, no information related to the selection of $160 \mathrm{rpm}$ as an initial parameter has been published. The Froude number explains the origin of this experimental parameter used in all RVA experiments.

In order to determine the apparent viscosity of suspensions, such as starch-water, it is necessary to determine the amount of fluid that added into the vessel will satisfy $\mathrm{Fr}=1$. Figure $2 \mathrm{~A}$ shows the Froude number values as a function of $\mathrm{N}(\mathrm{rpm})$ for different impeller diameters, Inspection of Figure 2A reveals that for each impeller diameter there is only one value of $\mathrm{N}$ that satisfies $\mathrm{Fr}=1$. It is noteworthy that as the impeller diameter increases, the RPM of the system decreases. However, it is necessary to take into account that others geometrical variables of the system, such as the vessel diameter and amount of fluid, have to change. The impeller diameter has to be close to the diameter of the vessel, to avoid vortices and allows the complete agitation of the system.

The aforementioned results only involve the mathematical sense of Froude number. From a physics point of view, if the Froude number is one, the system is perfectly agitated and no vortices are formed. Therefore, gravity and centrifugal acceleration are equal, and the system is called critical flow. If the Froude number is less than one, the system is not totally in agitation conditions, and some sectors of the surface are not moving. This is called subcritical flow. In the case of Froude number greater than one the system forms vortices and the flow regime is turbulent. This is known as supercritical flow. Figure 2B shows a schematic top view of the fluid under agitation for $\mathrm{Fr}<1, \mathrm{Fr}=1$, and $\mathrm{Fr}>1$. According to Metzner and Otto (1957), it is clear that for all calculations the fluid density has to remain constant and the changes in this parameter cannot be used outside the laminar flow region.

\subsubsection{Analysis of $\mathrm{K}_{\mathrm{c}}$}

Eq. 2 clearly indicates that $\mathrm{K}_{\mathrm{c}}$ involves all the parameters related to the impeller and vessel. The only non-geometrical value is represented by the height of the fluid. Lai et al. (2000) showed that the $\mathrm{K}_{\mathrm{c}}$ value is dependent on the geometry and also on the flow regime; however, this is an incorrect manner to interpret this parameter, because the flow regime is dependent on the unique solution of equation 3 for $\mathrm{Fr}=1$

In eq. 2, all geometrical parameters are fixed by choosing the vessel and impeller dimension; thus these conditions are constant during operation. Figure $3 \mathrm{~A}$ illustrates the relationship between $\mathrm{K}_{\mathrm{c}} \mathrm{vs} \mathrm{H}$ with $\mathrm{D}=0.05 \mathrm{~m}$ and the change of the coefficient $\mathrm{x} 2\left(0.5,1.0\right.$ and 2.0). It is noteworthy that these curves intercept at $\mathrm{K}_{\mathrm{c}}$ equal one.

\subsubsection{Analysis of the Reynolds number}

From eq. 4 , in the case of a fluid within certain experimental condition, the Reynolds number can be expressed as:

$$
R e=\frac{\rho N D^{2}}{\eta_{a}}
$$

Where $\eta_{a}$ (Pa.s) can be defined as the apparent viscosity of a fluid and satisfy the power equation and Fr is equal to one. This means that the Reynolds number has strong correlation with Fr. The next step to obtain a unique solution for equation 1 is introducing the constraint $\mathrm{Fr}=1$ :

$$
P_{0}=K_{c} R e^{m}
$$

A problem associated with obtaining the Re is the need to analyze the behaviors of the system in relation to the $\mathrm{m}$ exponent. Ruston et al. (1950) analyzed the relationship between the power number (Po) and the Reynolds number in $\log$ scale. They found that for $\operatorname{Re}<10$ the slope of the curve is -1 (see Figure $3 \mathrm{~B}$ ), and the regime is laminar. This means that eq. 9 can be written as:

$$
P_{0}=\frac{K_{C}}{R e}
$$

This expression is convenient because it allows to obtain the apparent viscosity of a sample independently of density. In the case of Rapid Visco Analyzer system for starch aqueous suspensions, it is not possible to measure the Reynolds number and the density change; however, the relation $\mathrm{Re} / \rho$ can be easily calculated. If the density 
remains constant, this relation describes the flow behaviors. If the Reynolds number remains constant, this relation describes the density changes. In the case starch-water suspensions, these usually show that the pasting profiles are obtained as a function of the temperature. It is thus possible to have changes in the density of the system due to $T$ increases for values greater than the gelatinization temperature (Tg). All this means that the pasting profiles must be analyzed in detail for $\mathrm{T}>\mathrm{Tg}$.

2.5.5 Analysis of the Power number

Replacing eq. 5 and eq. 8 for apparent viscosity in eq. 10 :

$$
\frac{P}{\rho N^{3} D^{5}}=\frac{K_{c} \eta_{a}}{\rho N D^{2}}
$$

The power consumption can also be written as:

$$
P=V I
$$

Where:

$\mathrm{V}$ is the voltage supplied to the motor of the impeller (Volts) and I is the current supplied to the motor of the impeller (Amp)

Substituting it is possible to find the following expression for the apparent viscosity using an impeller viscometer:

$$
\eta_{a}=\frac{V I}{K_{c} N^{2} D^{3}}
$$

This equation is a unique solution under the aforementioned restrictions and allows permits one to determine the apparent viscosity of a fluid by monitoring the changes in the voltage and current of the electro mechanical system used to move the impeller of the viscometer system.

According to these results, it is very important to establish the initial parameters that have to be used to carry out a pasting profile. Among them, the solid/water ratio for each experiment must be used in order to determine the apparent viscosity of a fluid, while taking into account the Froude number and the unique solution of the power equation. It is normal practice to develop a set of to study different materials, but it is still very important to establish the behaviors of the system for each specific case. This way, one can determine the complete experimental conditions needed to obtain a meaningful pasting profile.

\section{Results}

Figure 4A shows the particle size distributions (PSD) of starch sample (Newport Company) used in all the experiments. The average value of starch was $12.33 \pm 2.23 \mu \mathrm{m}$. Figure 4B shows a SEM image of starch granules taken at $2500 \mathrm{x}$ in which, it is clear that the starch is formed by separated individual particles. In order to study the pasting properties of starch aqueous suspensions, the operation conditions of the RVA system were: vessel diameter $0.037 \mathrm{~m}$, height $0.068 \mathrm{~m}$; impeller diameter $0.034 \mathrm{~m}$ and height $0.013 \mathrm{~m}$.

Figure 5A shows the DSC thermogram of starch-water system using different moisture contents (namely 70, 75, 80,84 and $87 \%$ ) and a heating rate of $5.7^{\circ} \mathrm{C} / \mathrm{min}$, which corresponds to the same heat rate used in RVA experiments. This thermogram was divided in three different regions according to the thermal behavior. Region Icorresponds to the temperatures range from 50 to about $56{ }^{\circ} \mathrm{C}$, in which no changes in the thermogram are present, indicating that in the range of temperature no endothermic or exothermic reaction take place. In region II, the endothermic reaction takes place. This region can be defined with precision by choosing the onset point at the beginning of the gelatinization peak and the termination at the end of it, which gives the temperature range for this event. In this region, the structural order of the starch granules was disrupted, and a fraction of amylose is exuded to the liquid. Finally region III is defined for temperatures up to gelatinization and $92{ }^{\circ} \mathrm{C}$, in which no thermal changes in the system were found. These conditions indicate that the whole system is gelatinized, forming a new phase composed by gelatinized starch granules, amylose and water.

Figure 5B shows the Te-To as a function of the temperature. It is evident that Te-To decreases as the water content increases. This range of temperature for the gelatinization process decreases around $30 \%$ when the water content increases only $16 \%$. Figure $5 \mathrm{C}$ shows the $\mathrm{Tg}$ as a function of the moisture content; it is clear that in this range of moisture no significant changes in the gelatinization peak are present, while the moisture content has more effect in the range of the gelatinization event (as can be seen in Figure 5B).

Figures $6 \mathrm{~A}, \mathrm{~B}$ and $\mathrm{C}$ show a characteristic pasting profile of starch aqueous suspensions, as well as the first and 
second derivatives as function of time, for a sample of $4 \mathrm{~g}$ of starch and $24 \mathrm{~g}$ of water. In order to understand the changes in the pasting profile, this was divided into five different time windows taking into account the DSC behaviors revealed in figure 5 (regions I, II and III). Additionally, for region I no changes in the viscosity values as function of the temperature and time are present. The same behavior is observed in the first and second derivatives. From a physical point of view, the starch granules do not exhibit water absorption and, by direct inspection of Figure 5A, no thermal changes take place.

The region II of the RVA profile is characterized by water absorption of the starch granules due to the increment of the temperature, and it is governed by the gelatinization process; is noticeable, however, that for the first part of this region (To to $\mathrm{Tg}$, see Figure 5A) the RVA system is not sensitive to the thermal changes in the starch granules. This response is due to the RVA system, because it senses the torque of the starch-water aqueous suspension. In the second part (Tg to Te) the RVA profile exhibits a non linear dependence as a function of time. In this region, the RVA system is sensing the end of the gelatinization process.

The sub-division of region II is confirmed by direct inspection of Figures5A and 6 . The width of the region II decreases as the water content increases (see Figure 5B). The change of the pasting profile exhibits an exponential behavior for the second part of this region. This is confirmed by the shape of the first and the second derivative of the RVA profile, which exhibit the same profile. In region II the changes in the viscosity are governed by the water absorption phenomena and the gelatinization of the starch granules as was confirmed by DSC experiments.

Region IIIis characterized by the increase of apparent viscosity, but a detailed inspection of the viscosity changes can be obtained in terms of the first derivate (dna/dt), the gelatinization according to DSC had finished (see region II). As a result, some starch granules exhibit amylose exudation, which is also a progressive phenomenon. The system is formed primarily by amylase-water, forming a new semi-network with completely different behavior. At this point, it is very important to take into account that according to the RVA system, the density of the system within the thermal profile does not exhibit any change; however, it is noteworthy that due to the high temperature and high water content, the density of the system tends to decrease. In the case of the second derivative for this region, it does not show significant changes indicating that the system remains in the same state.

For region IV, temperature remains constant, and the apparent viscosity of the system decreases. The system is now formed by disrupted starch; that is, exuded amylose in a water solution. No thermal changes are present in this region.

Whereas in region $\mathrm{V}$, the apparent viscosity increases as a consequence of the cooling process, and the retro-gradation process takes place. In the last two regions, the first and second derivatives do not exhibit any change, meaning that the pasting profile in these region is not time dependent.

Figure 7A shows the changes in the pasting profile as a function of the time for starch sample, whilst Figure 7B shows the Ln ( $\eta \mathrm{a}$ ) as a function of time for region II-b ( $4 \mathrm{~g}$ of starch and $24 \mathrm{~g}$ of water). As it was mentioned before, the exponential dependence between these variables is evident. Mathematically, this dependence can be expressed as:

$$
\eta_{a}=\eta_{0} e^{\frac{t}{\tau}}
$$

Where $\tau$ is the characteristic time, which is closely related to the water absorption of the starch granules. Here, $\eta_{0}$ is the initial viscosity value of the system (at the beginning of region II-b). For region II starch particles increase in size and remain intact, because the changes in their size are due to the swelling process. In the case of starch, the study of the changes of the slope of the pasting profile in this can reveal important information related to the initial physical state of the starch.

Figure 8 shows the pasting profile for different starch-water concentration, namely $1: 27 ; 2: 26 ; 3: 25,4: 24$, and 4.5:23.5 w/w. It is evident that at low starch concentrations $(1 \mathrm{~g})$, the sample exhibits very low apparent viscosity values and a weak peak viscosity. This is because at this concentration the system is diluted and no connectivity between starch granules or cumuli is present. According to Steeneken (1989), increasing the starch concentration eventually leads to a situation where the fully swollen granules just fill up the available space.

For starch concentrations of 2, 3, 4, and $4.5 \mathrm{~g}$ the peak viscosity increases, and is noticeable that the time to sense the swelling process also increases. The region II (see figures 5 and 6), which corresponds to exponential dependence of the viscosity, has a different growing rate. Then, the apparent viscosity increases as a function of 
the concentration, but the swelling process in each starch granule has to be the same.

The effect of filling space due to the increases of the starch concentration influences the apparent viscosity. If the starch concentration increases, the filling space decreases, and the system pass from a transition region to a concentrated region; the apparent viscosity of the systems increases too, as can be seen in the peak viscosity. Table 2 shows the pasting profile characteristics for different starch concentrations.

Figure 9A shows, for all the samples in region II-b the viscosity as a function of the time. These profiles evidence the exponential dependence of the viscosity changes as a function of time. Figure 9B shows the Ln ( $\eta$ a) as a function of time a curve in which linear dependence between apparent viscosity and time is observed. This is characteristic of a system under exponential dependence. Using the experimental data of $\operatorname{Ln}(\eta \mathrm{a})$ as a function of time, it is possible to obtain a characteristic time that revels the manner in which the viscosity increases in this region. Figure 10 shows the slope values (characteristic time) for different starch/water ratios. According to Steeneken (1989) it is possible to identify dilute, transition, and concentrated regimes using our methodology, however, it is possible to associate a characteristic time to identify and separate these regimes. According to this result the dilute regime is characterized by high $\tau$ value, while the concentration regimen is characterized by a low $\tau$ value (high slope). In terms of the changes of the slope as a function of time, these regimens exhibit a difference up to $800 \%$. An important feature for the region II is that the end of this region could be associated with the end of the gelatinization process of the starch granules in the aqueous suspension as can be seen in Figure 5 for the DSC experiments.

\section{Conclusions}

This work explains in detail, and for first time, a complete model to study and interpretation of a pasting profile of the starch aqueous suspension in the presence of a thermal profile. The model allows investigators to understand how RVA systems works and, for the first time, to obtain mathematically the $160 \mathrm{rpm}$ used for the operation conditions of the RVA system. According to the model the rpm of the system is fixed when the vessel and impeller dimensions are given.

The pasting profile shows the physicochemical changes of the starch aqueous suspension as a function of temperature and time, and allows the determination of the apparent viscosity of the sample under study. In the case of starch granules (Newport) the pasting profile can be divided in different regions that can be defined through the use of the DSC, establishing critical points in the pasting profile in terms of thermal changes. The swelling process (region II-b) has exponential behaviors. Pasting profiles can be used to identify the dilute, transition, and concentrated regimes of the starch aqueous suspensions. Using our methodology it was possible to associate a characteristic time $(\tau)$ with each one of the three regimes mentioned above. The dilute regime is characterized by high $\tau$ value, while the concentration regime is characterized by a low $\tau$ value (high slope).

\section{Acknowledgments}

A. A. Acosta-Osorio would like to thank CONACYT-Mexico for their financial support of his Ph. D. studies. Authors would also like to acknowledge Beatriz Millan Malo, and Alicia del Real for their technical support and Dr. Roberto Molina for editing the English content of this document.

\section{References}

Abdellatif, A., Marshal, P., Choplin, L., Chrissemant A. S., \& Bousmina, M. (2002). Quantitative analyisis of mixer-type rheometers using the Coutte analogy. The Canadian Journal of Chemical Engineering, 80, 1166-1174. http://onlinelibrary.wiley.com/doi/10.1002/cjce.5450800618/pdf

Bongenaar, J. J. T. M., Kossen N. W. F., Metz B., \& Meijiboom, F. W. (1973). A method for characterizing the rheological properties of viscous fermentation broths. Biotechnology and Bioengineering, 15, 201-206. http://dx.doi.org/10.1002/bit.260150115

Copeland L., Blazek, J. Salman, H., \& Tang M.C. (2009). Form and functionality of starch. Food hydrocolloids, 23, 1527-1534. http://dx.doi.org/10.1016/j.foodhyd.2008.09.016

Cornejo-Villegas, M. A., Acosta-Osorio, A. A., Rojas-Molina, I., Gutiérrez-Cortéz, E., Quiroga, M. A., Gaytán, M., Herrera, G., \& Rodríguez-García, M. E. (2010). Study of the physicochemical and pasting properties of instant corn flour added with calcium and fibers from nopal powder. Journal of Food Engineering, 96, 401-409. http://dx.doi.org/10.1016/j.jfoodeng.2009.08.014

Eriksson, I., Bolmstedt, U., \& Axelsson, A. (2002). Evaluation of a helical ribbon impeller as a viscosity measuring device for fluids foods with particles. Applied Rheology, 12, 303-308. http://polyphys-s01.ethz.ch/cgi-bin/AR/ar_contents?match=Bolmstedt.U 
Lai K. P., Steffe J. F., \& Ng P. K. W. (2000). Average shear rates in the rapid visco analyzer (RVA) mixing $\begin{array}{lllll}\text { system. Chemistry, } & \text { Cereal 714-716. }\end{array}$ http://cerealchemistry.aaccnet.org/doi/abs/10.1094/CCHEM.2000.77.6.714

Meadows F. (2002). Pasting properties in rice flour using rapid visco analyzer curves and first derivate. Cereal Chemistry, 79(4), 559-562. http://www.aaccnet.org/cerealchemistry/articles/2002/0605-03R.pdf

Metz B., Kossen N. W. F., \& van Suijdam J. C. (1979). The Rheology of mould suspensions. Advances in Biochemistry Engineering, 11, 103-156. http://www.springerlink.com/content/775mu35758500081/

Metzner A. B., \& Otto R. E. (1957). Agitation of non-Newtonian fluids. AIChE Journal, 3, 3-10. http://dx.doi.org/10.1002/aic.690030103

Novotná P., Landfeld A., Karel K., Houska M., \& Strohalm J. (2001). Use of helical ribbon mixer for measurement of rheological propiertes of fuit pulps. Czech Journal Food Science, 19(4), 148-153. http://agris.fao.org/agris-search/search/display.do?f=2001/CZ/CZ01005.xml;CZ2001001125

Palacios-Fonseca A. J., Vazquez-Ramos C., \& Rodriguez-Garcia M. E. (2009). Physicochemical characterizing of industrial and traditional nixtamalized. Journal of Food Engineering, 93, 45-51. http://dx.doi.org/10.1016/j.jfoodeng.2008.12.030

Pimenova N. V., \& Hanley T. R. (2003). Measurement of rheological properties of corn stover suspensions. Applied Biochemistry and Biotechnology, 105-108, 383-392. http://dx.doi.org/10.1385/ABAB:106:1-3:383

Quemada D. (1977). Rheology of concentrated disperse systems and minimum energy dissipation principle: I.

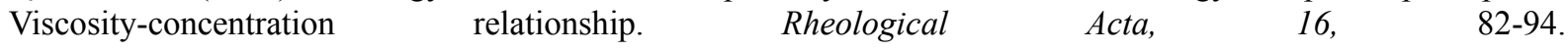
http://www.springerlink.com/content/h7836430m0743m68/fulltext.pdf

Quemada D. (1978). Rheology of concentrated disperse systems: II. A model for non-newtonian shear viscosity $\begin{array}{lllll}\text { in steady } & \text { flows. } & \text { Rheological } & \text { Acta, } & \text { 632-642. }\end{array}$ http://www.springerlink.com/content/k2265706485n830u/fulltext.pdf

Quemada D. (1978). Rheology of concentrated disperse systems: III. General features of the proposed non-newtonian model. Comparision with experimental data. Rheological Acta, 17, 643-653. http://www.springerlink.com/content/k12u234725748069/fulltext.pdf

Rushton J. H., Costich E. W., \& Everett H. J. (1950). Power characteristics of mixing impellers. Chemistry Engineering Progress, 46, 395-404.

Steeneken P. A. M. (1989). Rheological properties of aqueous suspensions of swollen starch granules. Carbohydrate polymers, 11, 23-42. http://dx.doi.org/10.1016/0144-8617(89)90041-6

Yamin F.F., Svendsen L., \& White P. J. (1997). Thermal properties of corn starch extraction intermediates by differential scanning calorimetry. Cereal chemestry, 74(4), 407-411. http://cerealchemistry.aaccnet.org/doi/abs/10.1094/CCHEM.1997.74.4.407 
Table 1. Mechanical, geometrical, and physics nomenclature used

\begin{tabular}{|l|l|}
\hline & Variable name \\
\hline $\mathrm{C}$ & Height impeller of bottom \\
\hline $\mathrm{D}$ & Impeller diameter \\
\hline $\mathrm{Fr}$ & Froude number \\
\hline $\mathrm{g}$ & Gravity \\
\hline $\mathrm{H}$ & Liquid depth \\
\hline $\mathrm{I}$ & Current \\
\hline $\mathrm{J}$ & Width of the blades \\
\hline$K_{c}$ & Impeller and environment characteristics \\
\hline $\mathrm{L}_{\mathrm{b}}$ & Length of the blades \\
\hline $\mathrm{N}$ & Revolution per second \\
\hline$\eta_{\mathrm{a}}$ & Apparent viscosity \\
\hline $\mathrm{P}$ & Power \\
\hline $\mathrm{P}_{0}$ & Power number \\
\hline $\mathrm{Re}$ & Reynolds number \\
\hline $\mathrm{S}$ & Pitch of impeller \\
\hline $\mathrm{T}_{\mathrm{d}}$ & Tank diameter \\
\hline $\mathrm{V}$ & Voltage \\
\hline & Density \\
\hline & \\
\hline
\end{tabular}

Table 2. Pasting characteristic for different concentrations starch-water determined by RVA systems

\begin{tabular}{|c|c|c|c|c|c|c|c|c|c|c|}
\hline $\begin{array}{c}\text { Samples } \\
(\mathrm{g})\end{array}$ & $\begin{array}{c}\text { Rate } \\
\mathrm{w} / \mathrm{v} \\
(\mathrm{g} / \mathrm{ml})\end{array}$ & $\begin{array}{c}\text { PastingTemp } \\
\text { erature } \\
\left({ }^{\circ} \mathrm{C}\right)\end{array}$ & $\begin{array}{c}\text { Pasting } \\
\text { time } \\
(\mathrm{s})\end{array}$ & $\begin{array}{c}\text { Peakvisc } \\
\text { osity } \\
(\mathrm{mPa} \mathrm{s})\end{array}$ & $\begin{array}{c}\text { Breakdown } \\
(\mathrm{mPa} \mathrm{s})\end{array}$ & $\begin{array}{c}\text { Holding } \\
\text { strength } \\
(\mathrm{mPa} \mathrm{s})\end{array}$ & $\begin{array}{c}\text { Setback } \\
(\mathrm{mPa} \mathrm{s})\end{array}$ & $\begin{array}{c}\text { Final } \\
\text { viscosity } \\
(\mathrm{mPa} \mathrm{s})\end{array}$ & $\begin{array}{c}\text { Peak } \\
\text { time } \\
(\mathrm{s})\end{array}$ & $\begin{array}{c}\text { PeakTemper } \\
\text { ature } \\
\left({ }^{\circ} \mathrm{C}\right)\end{array}$ \\
\hline 1 & 0.0370 & 91.05 & 516 & 80 & 8 & 72 & 2 & 74 & 688 & 91 \\
\hline 2 & 0.0769 & 87.2 & 468 & 890 & 245 & 645 & 38 & 683 & 564 & 91 \\
\hline 3 & 0.1200 & 79.55 & 384 & 3156 & 1469 & 1687 & 935 & 2622 & 516 & 91 \\
\hline 4 & 0.1667 & 70.75 & 288 & 8095 & 4662 & 3433 & 3491 & 6924 & 468 & 87.2 \\
\hline 4.5 & 0.1915 & 69.95 & 280 & 11823 & 7509 & 4314 & 5422 & 9736 & 440 & 84.6 \\
\hline
\end{tabular}




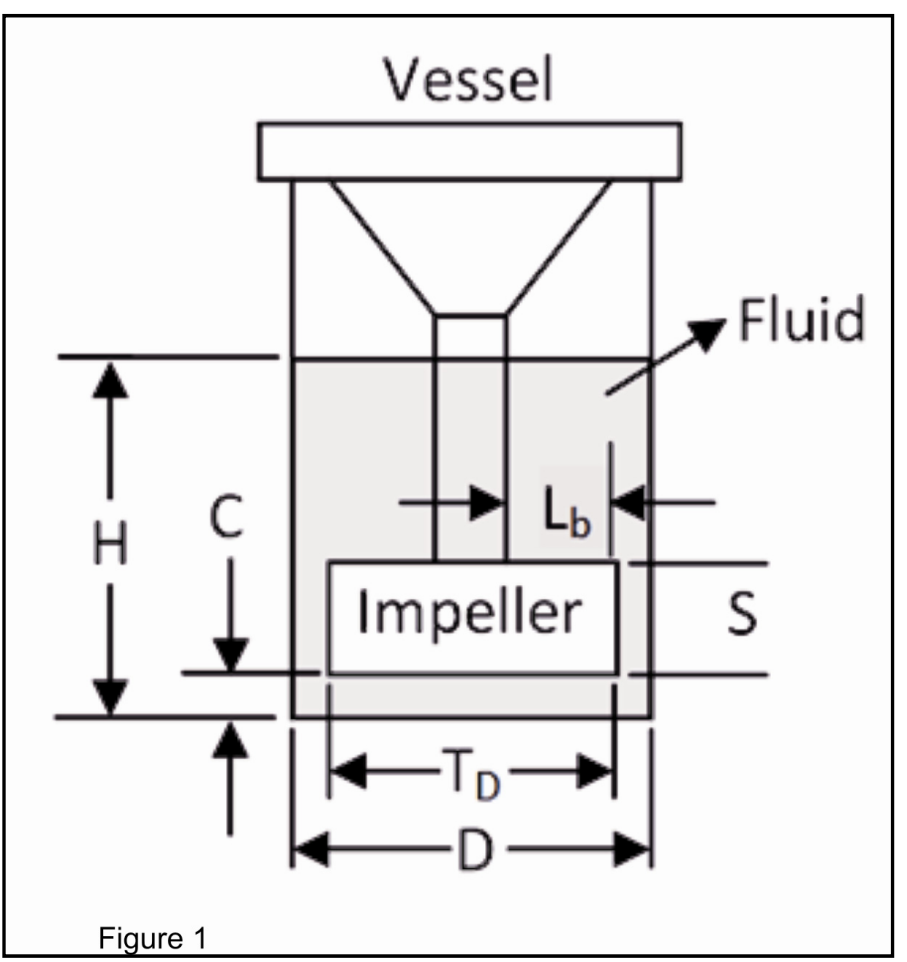

Figure 1. Graphic representation of impeller, vessel geometries and fluids of the impeller viscometer system

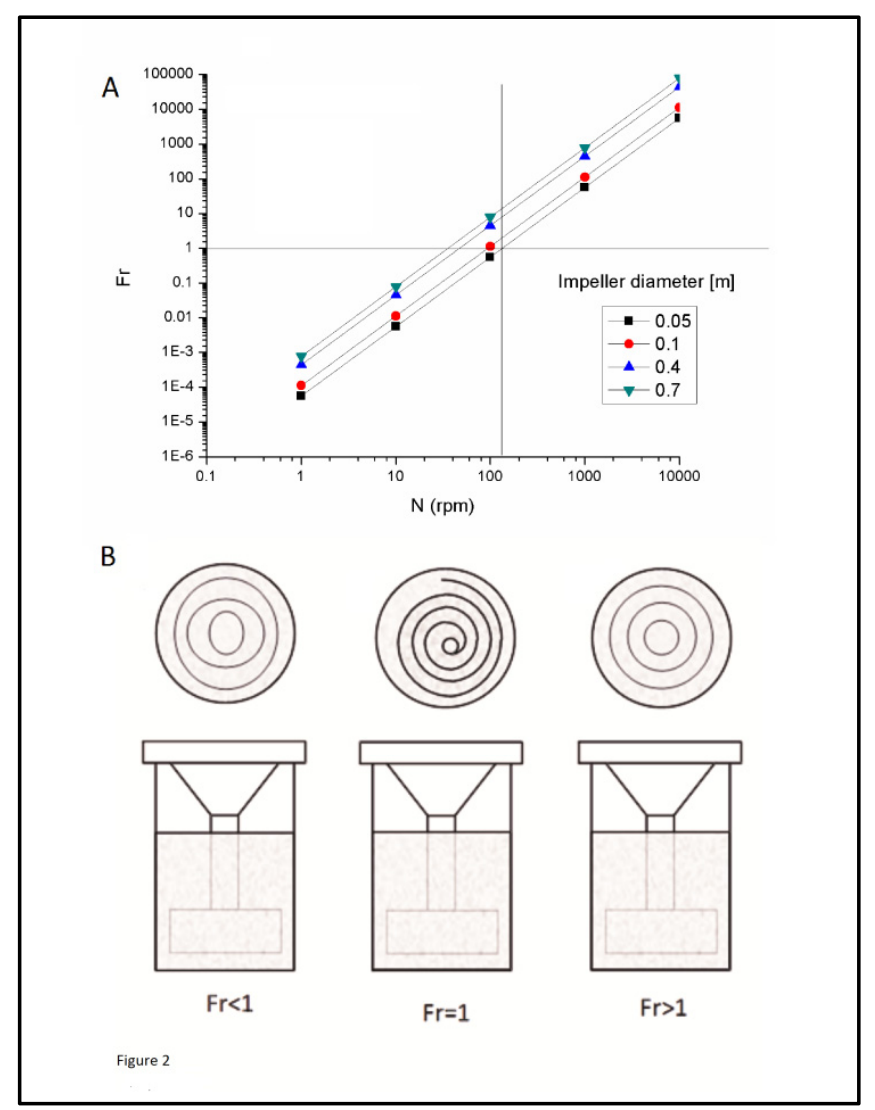

Figure 2. A. Froude values of a function of the $\mathrm{N}$ for different impeller diameters. B. Schematic top view of the fluid under agitation for $\mathrm{Fr}<1, \mathrm{Fr}=1, \mathrm{Fr}>1$ respectively 


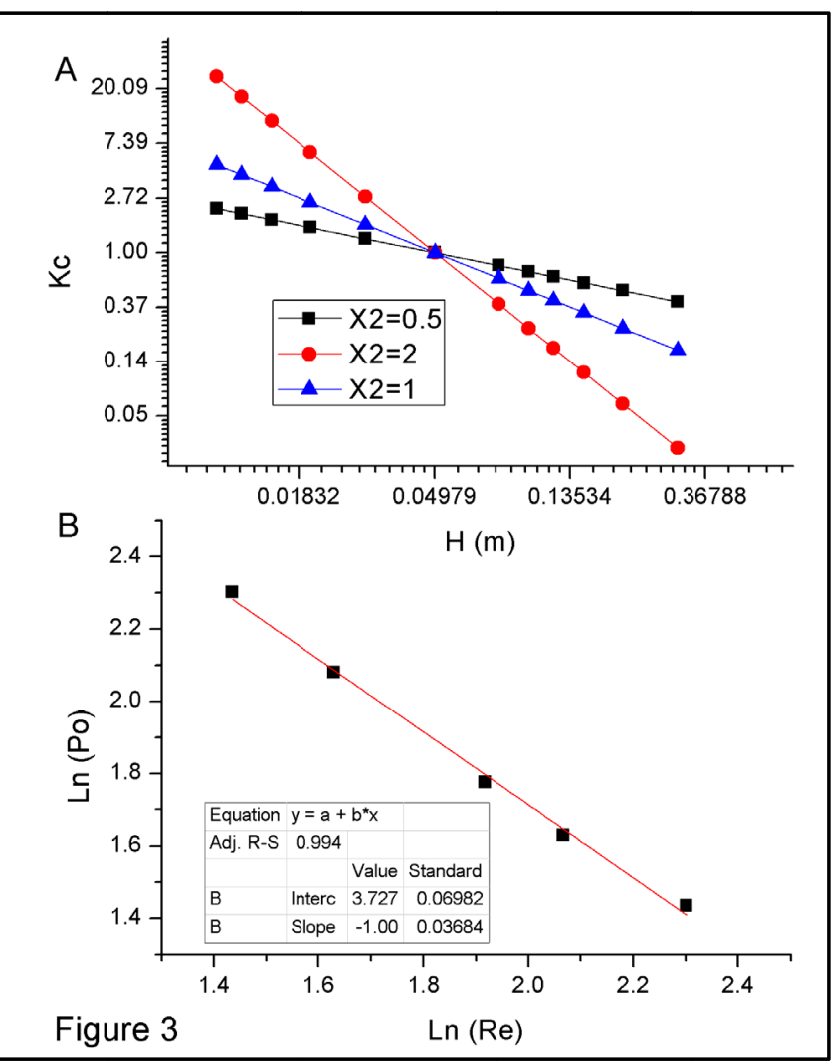

Figure 3. A. Relationship between $\mathrm{K}_{\mathrm{c}} \mathrm{vs} \mathrm{H}$ with $\mathrm{D}=0.05 \mathrm{~m}$ for coefficient $\mathrm{x} 2=0.5, \mathrm{x} 2=1.0, \mathrm{x} 2=2.0$. $\mathrm{B}$.

Reelationship between Power number (Po) and the Reynolds number (Re) in the log scale, for Re value minor than 10
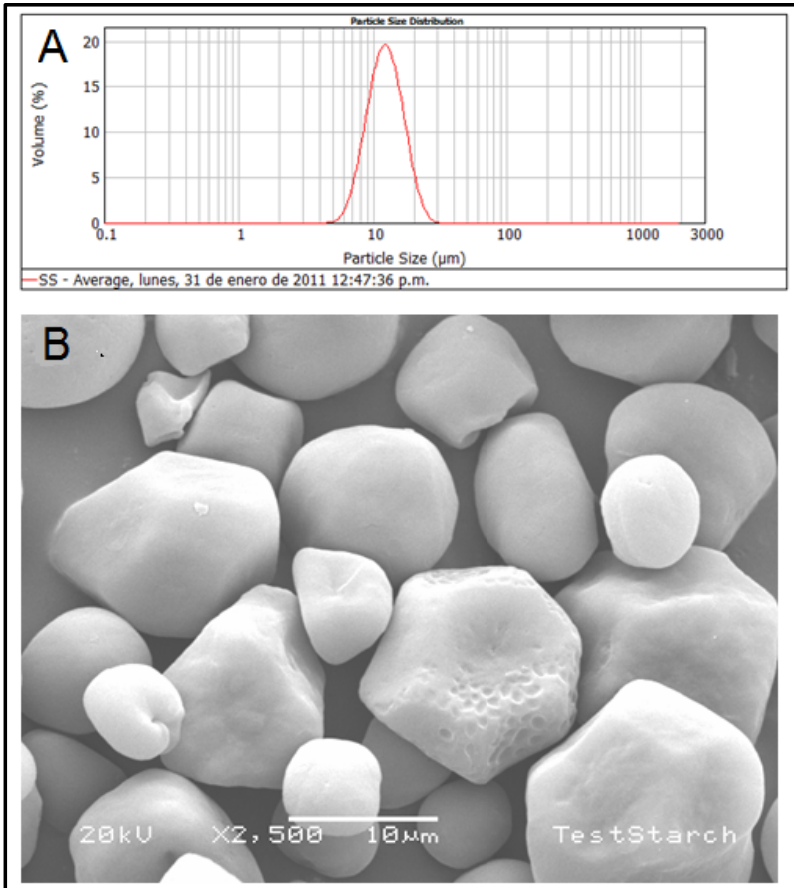

Figure 4

Figure 4. A. Particle size distributions of the starch sample (SS) used for all test. B. Starch sample photographic obtained by scanning electronic microscopic (SEM) 


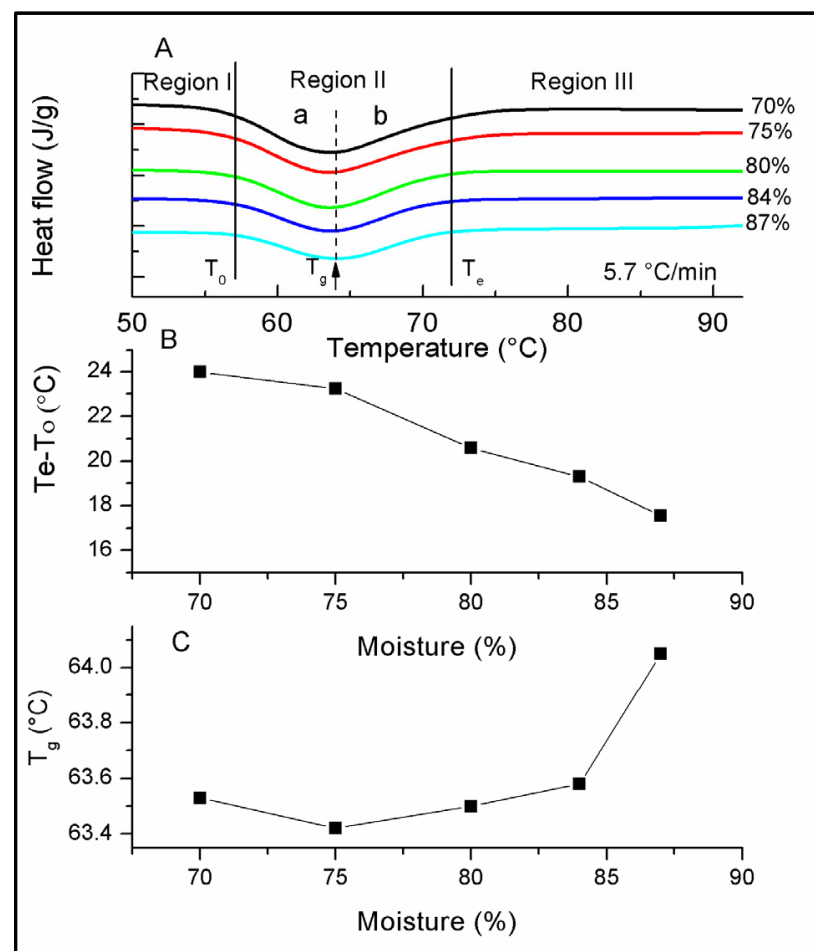

Figure 5

Figure 5. A.DSC thermogram of starch-water system using different moisture contents (70, 75, 80, 84 and $87 \%)$ and $5.7^{\circ} \mathrm{C} / \mathrm{min}$. B.To-Te of gelatinization process. C. Tg as a function of the moisture content

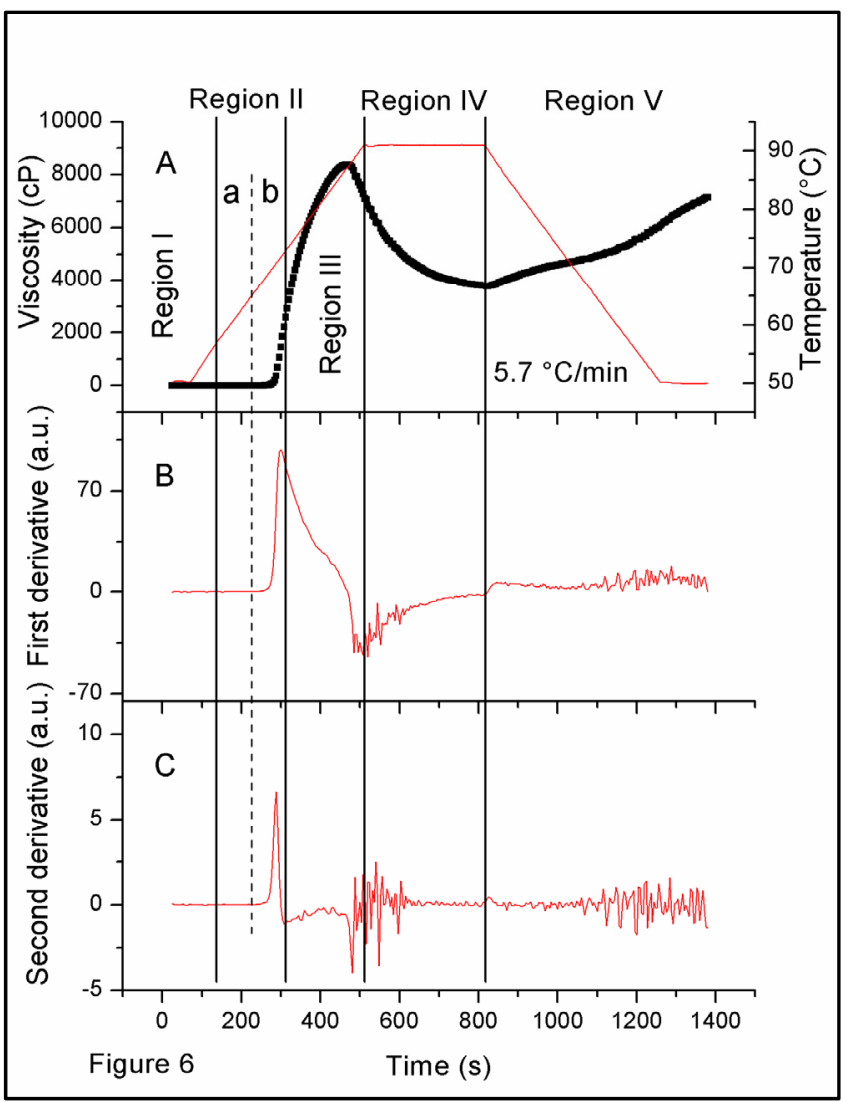

Figure 6. A. Pasting profile of starch (Newport) used for calibration of RVA systems B.First derivative of the viscosity profile as a function of the time. C. Second derivate of the viscosity profile as a function of the time 


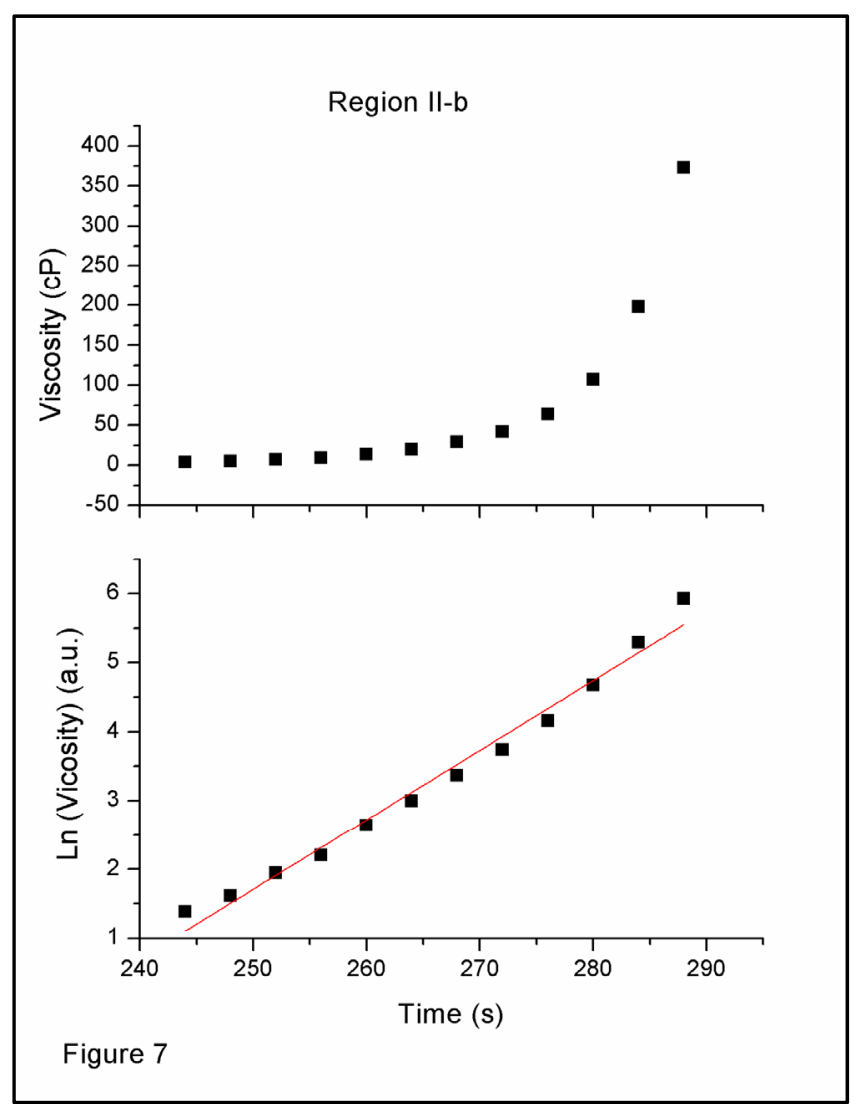

Figure 7. A. Pasting profile of the region 2 as a function of the time. B. Ln (viscosity) as a function of the time. Both are starch sample (SS)

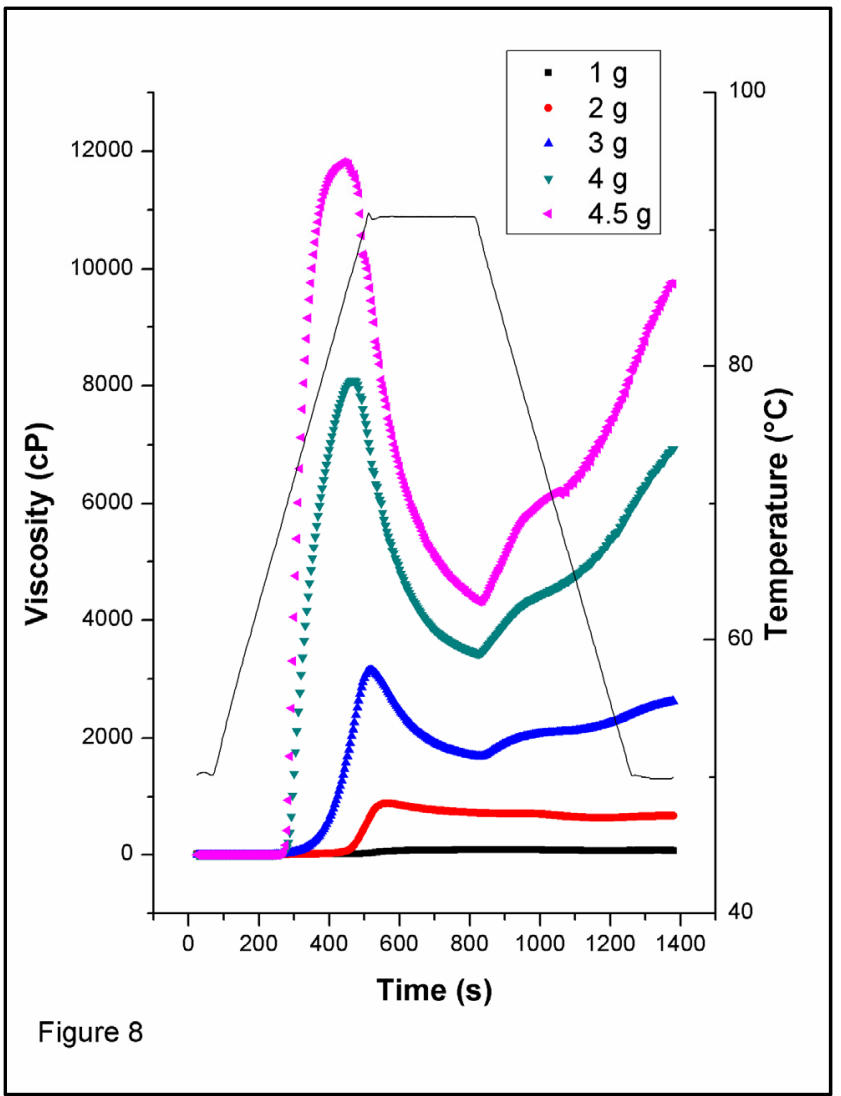

Figure 8. A. Pasting profiles for different concentrations starch-water. B. Ln (viscosity) as a function of the time 


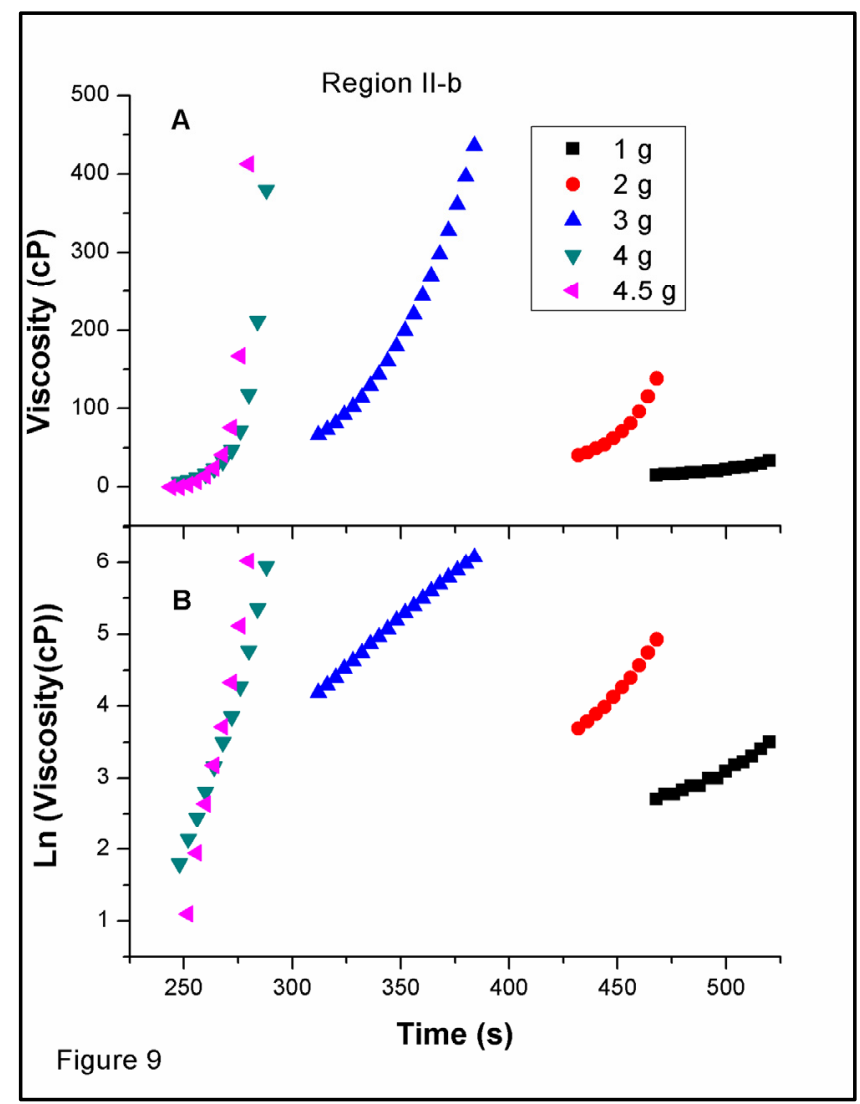

Figure 9. A. Pasting profile of the region 2 as a function of the time for different concentrations. B. Ln (viscosity) as a function of the time for different concentrations

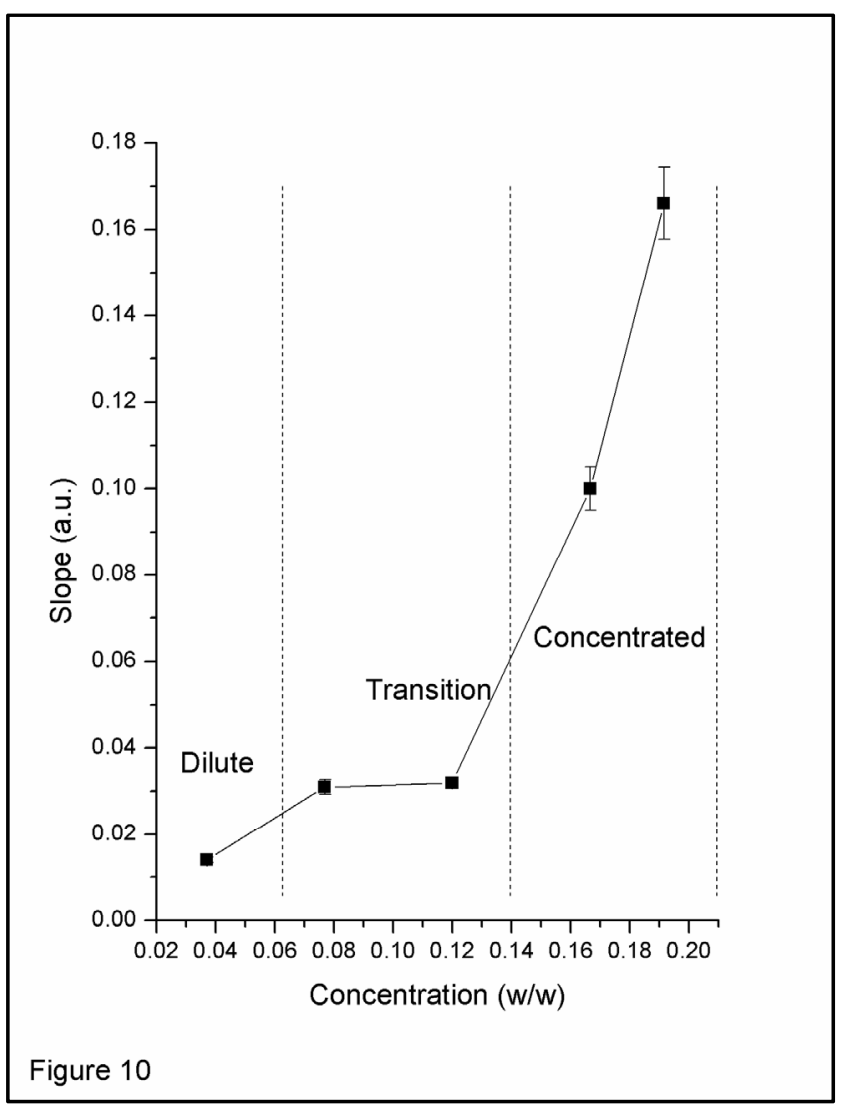

Figure 10. Slope values of the pasting profile in region 2 (characteristic time) as a function starch/water ratio 